\title{
Public Health Institutions and Major Epidemic Prevention and Control-Narrative Analysis Based on American CDC Control of Ebola Virus
}

\author{
Ye Zheng \\ School of Humanities, Economics, and Law / School of Management, Northwestern \\ Polytechnical University \\ Shaanxi, 710072, China \\ School of Public Policy, University of Massachusetts Amherst \\ Amherst, 01003, USA \\ E-mail: lbxjbzy@nwpu.edu.cn \\ Yunshan Jiang \\ School of Humanities, Economics, and Law, Northwestern Polytechnical University \\ Shaanxi, 710072, China \\ E-mail: 708843559@qq.com
}

\begin{abstract}
Kexin Qin
School of Humanities, Economics, and Law, Northwestern Polytechnical University Shaanxi, 710072, China

E-mail: 708843559@qq.com
\end{abstract}

Received: Oct. 16, 2020 Accepted: Nov. 24, 2020 Online published: Dec. 7, 2020

doi:10.5296/jpag.v10i4.17844 URL: https://doi.org/10.5296/jpag.v10i4.17844

\begin{abstract}
In the past 10 years, various sudden public outbreaks of diseases worldwide have posed great threats to the economic and social development of countries. However, there is a lack of case studies and empirical studies on the fight against major outbreaks in foreign public health
\end{abstract}


institutions. Based on a review of classical materials and narrative research methods, this study combs the institutional profile, function allocation, and funding input of the American Centers for Disease Control and Prevention (CDC) and focuses on the CDC's important measures and experiences in preventing and controlling the Ebola virus in West Africa during 2014-2015. According to the research, the main characteristics of CDC's epidemic prevention and control in the United States are effective organizational structure and system, as well as the abilities of emergency management of rapid response. Furthermore, these two advantages and characteristics have penetrated the construction of the incident management system, adoption of specialized technical means and tools, and wide cooperation network and organizational coordination. Accordingly, the enlightenment of public health institutions regarding "epidemic prevention" and "anti-epidemic" is proposed from two aspects: system construction and ability enhancement.

Keywords: public health institutions, epidemic prevention and control, CDC, Ebola virus, narrative analysis

\section{Introduction}

Against the background of globalization and informationization, some developed and developing countries are facing rapid economic development and various unprecedented public epidemics, which greatly affect national wealth and personal life safety. Furthermore, governments and the public are apprehensive about emerging infectious diseases caused by microbes spreading in a region, country, or worldwide or in small outbreaks such as that of swine flu (Mukherjee, 2017). Simultaneously, public health institutions are important for public health decision-making and influencing public trust. Some scholars have stated that public trust in public health institutions is always seen as an important prerequisite and basis for citizens to comply with public health decisions and norms (Robert, 2017). Recently, to contain health threats as soon as possible and ensure global public health security, World Health Organization (WHO; 2014) called upon all countries to identify and respond promptly to public health emergencies and cooperate globally when necessary. Moreover, in the global epidemic cooperation network system, national public health institutions play an important role.

In response to the global epidemic, in addition to WHO, the U.S. Centers for Disease Control and Prevention (CDC) has made positive contributions, especially after the 2002 severe acute respiratory syndrome outbreak and 2014 Ebola outbreak in West Africa. The CDC has also launched many effective initiatives to control epidemics. To protect American citizens and the international community from health-related threats, the CDC has established a global health protection platform in collaboration with the Ministry of Health and partnerships with WHO, relevant non-governmental organizations, and academic institutions. Moreover, CDC country offices have been established, and institutional project plans related to influenza, emerging zoonoses, human immunodeficiency virus, malaria, and polio have been developed (Schuchat \& Tappero, 2014). The CDC is also committed to enhancing the core competencies of interdepartmental cooperation to ensure protection against specific diseases and new and unpredictable health threats through initiatives such as the Field Epidemiology Training 


\section{Ml Macrothink}

Journal of Public Administration and Governance

ISSN 2161-7104

2020, Vol. 10, No. 4

Programme and Global Disease Detection Network (Jones et al., 2014; Schneider et al., 2011). Thus, CDC's experience and practice in prevention and control of global diseases and epidemics are worth studying and exploring. Accordingly, The research objectives of this paper are: (1)Based on the narrative inquiry, to compile an overview of the US CDC organizations and their contributions and measures in the prevention and control of Ebola virus.(2)To build an implementation framework for the prevention and control of major epidemics in public health institutions, and provide experience and theoretical guidance for the prevention and control of major epidemics in public health institutions.

\section{Literature on Public Health Institutions' Epidemic Prevention and Control}

\subsection{Current Situation of Overall Research}

Over the past 30 years, at least 30 new infectious diseases have emerged globally, threatening the lives and health of millions of people, and many diseases that were no longer a public health threat are reemerging (Mukherjee, 2017). Scholars from various countries have conducted in-depth studies on major public epidemic prevention and control issues. The retrieval of relevant Science Citation Index and Social Science Citation Index journal literature from the Web of Science database on public epidemic and disease control resulted in 1,954 related documents, mainly on public environment and occupational health (534), infectious diseases (413), immunology (141), and other fields. A further search for "public epidemic and disease control" and "public health agency" retrieved 120 important documents on public environment and occupational health (48), infectious diseases (16), internal general medicine (13), and immunology (8); the earliest results date back to 1990. Table 1 lists the most frequently cited classic literature from top international journals.

Table 1. Top 10 citations in classic journals from 1990 to 2020

\begin{tabular}{|c|c|c|c|c|}
\hline No. & Title & $\begin{array}{c}\text { Publication } \\
\text { (Impact Factor) }\end{array}$ & $\begin{array}{l}\text { Indexed } \\
\text { Frequency }\end{array}$ & Author and Year \\
\hline 1 & $\begin{array}{l}\text { Smallpox as a biological weapon: } \\
\text { Medical and public health } \\
\text { management }\end{array}$ & $\begin{array}{l}\text { Journal of the American } \\
\text { Medical Association } \\
\qquad(51.273)\end{array}$ & 553 & $\begin{array}{l}\text { Henderson et al. } \\
\qquad \text { (1999) }\end{array}$ \\
\hline 2 & $\begin{array}{l}\text { Triple-reassortant swine influenza A } \\
\text { (H1) in humans in the United States, } \\
2005-2009\end{array}$ & $\begin{array}{c}\text { New England Journal of } \\
\text { Medicine (70.67) }\end{array}$ & 413 & Shinde et al. (2009) \\
\hline 3 & $\begin{array}{l}\text { Conquering the intolerable burden of } \\
\text { malaria: What's new, what's needed: } \\
\text { A summary }\end{array}$ & $\begin{array}{l}\text { American Journal of } \\
\text { Tropical Medicine and } \\
\text { Hygiene (2.315) }\end{array}$ & 405 & $\begin{array}{c}\text { Breman, Alilio, and } \\
\text { Mills (2004) }\end{array}$ \\
\hline 4 & $\begin{array}{l}\text { Globalisation and the prevention and } \\
\text { control of non-communicable } \\
\text { disease: The neglected chronic } \\
\text { diseases of adults }\end{array}$ & Lancet (59.102) & 268 & $\begin{array}{l}\text { Beaglehole and } \\
\text { Yach (2003) }\end{array}$ \\
\hline 5 & $\begin{array}{l}\text { Globalization, coca-colonization and } \\
\text { the chronic disease epidemic: Can the } \\
\text { Doomsday scenario be averted? }\end{array}$ & $\begin{array}{l}\text { Journal of Internal } \\
\text { Medicine (6.051) }\end{array}$ & 257 & Zimmet (2000) \\
\hline
\end{tabular}


6

Methadone maintenance treatment

(MMT): A review of historical and clinical issues

7

Human African trypanosomiasis: An emerging public health crisis

Climate change and vector-borne

8

diseases: What are the implications

for public health research and policy?

West Nile virus in the United States:

Guidelines for detection, prevention,

and control

10

Emerging role of Zika virus in
Mount Sinai Journal of

Medicine (1.623)

British Bulletin Medicine

(2.804)

Philosophical Transactions of the Royal

Science-Biological

Sciences (6.139)

Viral Immunology

(1.417)

Clinical of Microbiology

Reviews (17.75)
245

113

78

adverse fetal and neonatal outcomes et al. (2015)

Joseph, Stancliff,

and Langrod (2000)

Smith, Pepin, and

Stich (1998)

Campbell-Lendrum

Gubler et al. (2000)

Panchaud et al.

(2016)

\subsection{Research on Prevention and Control of Infectious Diseases}

Based on 10 articles with the highest citation frequency, scholars mainly put forward evidence from clinical medical research on infectious and non-communicable diseases and the corresponding intervention measures, diagnosis, and treatment methods. Regarding public health institutions' response to infectious diseases, scholars such as Henderson et al. (1999) believed that after smallpox virus infection, public health institutions should isolate infected persons as soon as possible, observe and monitor contacts, and conduct targeted selection of vaccination programs to effectively control further spread of the virus. Breman, Alilio, and Mills (2004) found that effective malaria control initiatives require government agencies to implement rational public policies, as market forces usually only promote the sale of drugs and the use of other related interventions and are thus not effective in controlling the epidemic. WHO listed the Zika virus outbreak as a global public health emergency because of its rapid spread and harmfulness (Panchaud et al., 2016). Several scholars proposed five strategies for the public health sector to prevent and control Zika virus, including intercepting animal life cycles (preventing media from growing in their native environment), reducing vulnerability to infection, limiting the source of urban population, and ensuring appropriate drainage and garbage management to block carrier proliferation (Weaver, 2013).

\subsection{Research on Prevention and Control of Non-Communicable Diseases}

With the resurgence of devastating infectious diseases, including AIDS, Ebola, Zika, and tuberculosis, international and regional public institutions are under pressure to address non-communicable diseases (Zimmet, 2000). Beaglehole and Yach (2003) noted that globalization is an important determinant of the prevalence of non-communicable diseases because it directly affects population risks and indirectly affects national economies and health systems. The current globalization of production and marketing activities in the tobacco and alcohol sector challenges policymakers and public health practitioners and requires comprehensive policy initiatives by governments and non-governmental organizations (Beaglehole \& Yach, 2003). In addressing the risk of diabetes, international 
diabetes and public health institutions must persuade and mobilize politicians; other international agencies such as the United Nations Development Programme, UNICEF, and World Bank; and international non-governmental organizations related to non-communicable diseases to address socio-economic, public nutrition, and health issues together (Zimmet, 2000). Most existing studies agreed that climate change is closely related to disease rates. For public health institutions, the most urgent need is strengthening current disease control efforts to reduce disease incidence and manage short-term climate risks, which will increase resilience to long-term climate change (Campbell-Lendrum et al., 2015).

\subsection{Review of the Study}

WHO adopted and revised the International Health Regulations in 2005, which must be strictly observed and implemented by member states. It also developed several prevention and control plans for public epidemics. However, because the country and region's political system and economic development are different, and the medical system have their own emphases, it is difficult to issue strategic guidance plans for epidemic prevention and control with wide universality. This leads to a public epidemic, and disease prevention and control are still major problems globally. Although existing studies present prevention and control strategies with suggestions for public epidemics and diseases from the clinical medicine and evidence evaluation perspectives, they do not consider public management, especially based on narrative analysis. Public health institutions should thus systematically examine the public epidemic crisis process. Although major public epidemic crises must be dealt with through combined efforts of the government, society, public, and other forces, public health institutions are undeniably important in the prevention and control process, and this needs to be deeply studied and discussed.

\section{Research Design}

\subsection{Narrative Research}

Narrative inquiry is a qualitative research method to obtain explanatory understanding by deconstructing, combing, and integrating narrative materials (stories) (Xu, 2015). From the development performance perspective, narrative research began in humanities and social sciences in the 1980s. Currently, narrative research is widely used in pedagogy, psychology, literature, and other disciplines, as well as in economics and management. In public management, some studies on public organizations' performance reports use narrative research methods (Anderson \& Gerbing, 1988). Narrative studies, compared with other research methods, remind researchers to identify inner "structures" of facts, rather than only using external frameworks to distort or abuse facts. It emphasizes the use of story metaphors to help create order, construct texts in particular contexts, and form theoretical models (Gao, 2020; Liu, 2002). To reflect the CDC's Ebola prevention and control incident more completely, this study proposes the narrative research method.

\subsection{Main Processes and Key Steps of Narrative Research}

Narrative research has no fixed steps: it pays more attention to the open research process but opposes the regular system program (Gao, 2020). Combining the discussion of the basic path 
of narrative research by scholars and the research reality, we establish the four research steps of narrative analysis in this paper: (1) Identifying the research problems(2)Determining research objects(3)Collecting stories and constructing live texts(4)Writing research texts and forming analytical reports. Accordingly, this study deconstructs and combs narrative materials such as the evolution of CDC's institutions, organizational structure, budget, main contributions in preventing and controlling Ebola virus, and intervention measures. The research framework is shown in Figure 1.

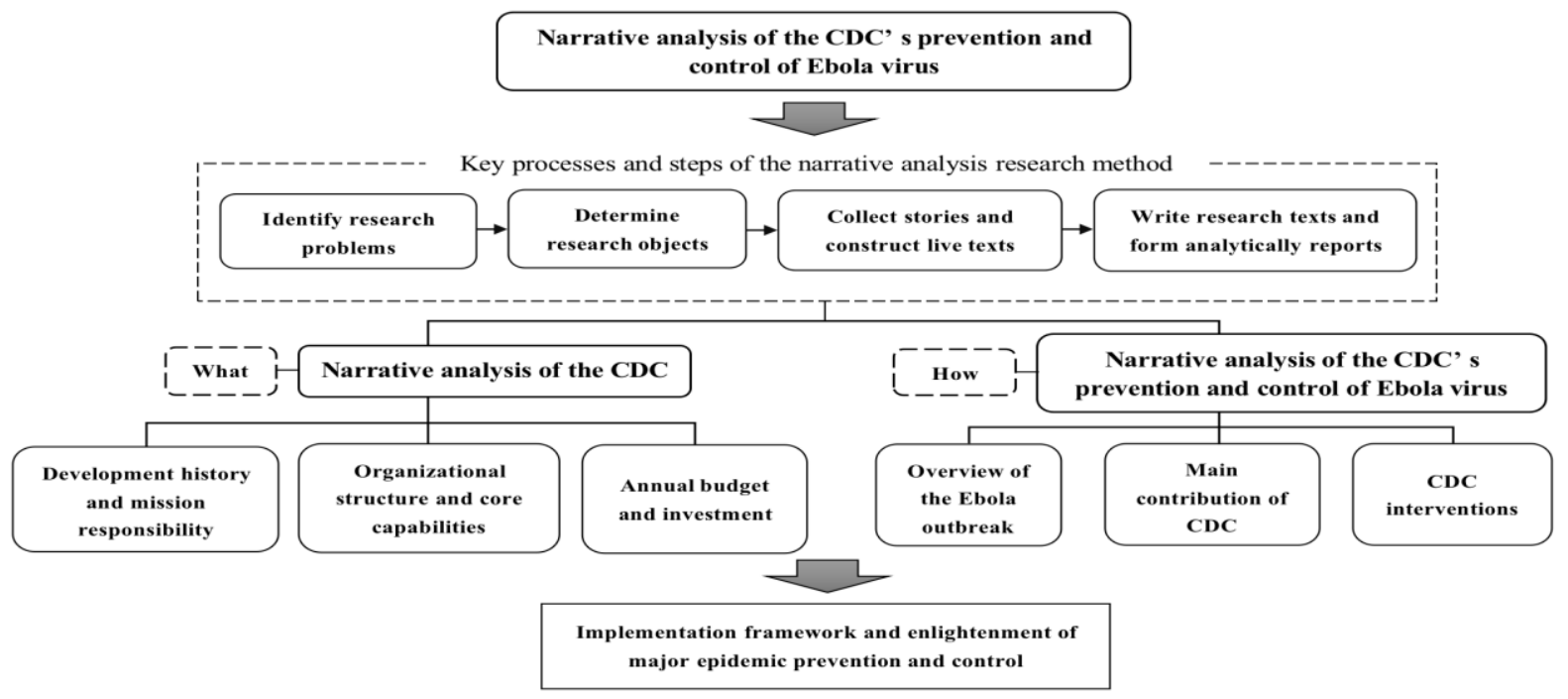

Figure 1. Narrative research framework. CDC: Centers for Disease Control and Prevention

\subsubsection{Identify Research Issues}

Here, the research problem originates from various phenomena in practice, and researchers must identify concisely individual phenomena worth exploring and implicit research problems (Fu \& Tian, 2008). In long-term public health practice, various countries' public health institutions are indispensable in responding to sudden outbreaks, but there is lack of case studies on their fight against major outbreaks. Therefore, this study focuses on foreign public health institutions and major epidemic prevention and control to collect narrative materials and analysis, forming two core research questions: (1) "What" is the basic overview of the CDC and its organizational structure? (2) "How" does the CDC fight major outbreaks?

\subsubsection{Selection of Subjects}

The U.S. is considered to have one of the best global public health management systems (Yuan, 2020). The CDC, established in July 1946, has made positive contributions toward preventing and responding to major outbreaks in the U.S. and worldwide. Today, CDC is the leading health promotion and disease prevention agency in the U.S. (Yuan, 2020). Particularly in response to the Ebola outbreak in 2014, they developed a series of effective prevention and control measures to curb the virus's spread and were recognized by international authorities such as WHO and others. Accordingly, this study selects the typical event of CDC's response to Ebola virus as the research object, collects relevant narrative stories, and carries out narrative research. 


\subsubsection{Collect Stories and Construct Live Texts}

The story in this study refers to the performance of CDC against Ebola virus. Performance stories can be presented as performance or policy reports (Wu, Ma, \& Zheng, 2009; Yan, Wu, $\&$ Ma, 2010). Based on the material(data) collected, this study's performance stories are mainly derived from, for example, official performance reports (e.g., Ebola Response Study published by the CDC), official policy texts (e.g., epidemic prevention initiative published by the CDC and Ebola Situation Statement published by the White House), official data information (e.g., confirmed patient data and morbidity and mortality data), and image data, thus amounting to 140,000 words. Although these are mainly used materials, they are a true record and reflection of the fight against Ebola virus and have important research value. Upon collecting and integrating these data, this study's the field text data are constructed according to the development context of events.

\subsubsection{Write Research Texts and Form Analytical Reports}

Before writing the research text, we need to transform the field text into the research text. For this, we must organize and summarize the field text repeatedly. Clandinin and Connelly (2003) described this as a "back and forth" process (Anderson \& Gerbing, 1988; Fu \& Tian, 2008; Gao, 2020; Liu, 2002; Xu, 2015; Wu et al., 2009; Yan et al., 2010; Yuan, 2020). Before completing the analysis report, three graduate students combed the field text materials in many rounds and then classified them into different research texts according to the field texts' type and content. Finally, according to the research text analysis, the research report (paper) was written.

\section{Narrative Analysis of American CDC Organizations}

\subsection{CDC's Development and Mission Responsibilities}

CDC is the first federal health organization founded by the U.S. as an agency of the Department of Health and Human Services; it is headquartered in Atlanta, Georgia, and has more than 17,000 employees worldwide. As a government agency, CDC focuses on the development and application of disease prevention and control, environmental health, occupational health, health promotion, prevention, and education activities aimed at improving people's health. Its website is updated in a timely manner, providing all kinds of true and reliable data for the protection of public health and safety, and promoting national health and scientific decision-making conducive to public life and health through partnerships with national health authorities and other international organizations. Table 2 describes CDC's development since its creation.

CDC aims to "prevent and control diseases, injuries and disabilities, promote health and improve quality of life (CDC, 2020)."The prevention and control of communicable diseases remains its main task. CDC's responsibilities have not changed since its inception. Its earliest role was studying the control of a single disease in a certain area of the U.S., gradually expanding its jurisdiction to cover many chronic diseases, occupational disorders, and social diseases such as violence and accidents, in addition to infectious diseases. CDC's efforts have greatly improved human life and, in its first 70 years of history, contributed significantly to 
the reduction and even elimination of infectious diseases in the U.S. and worldwide (Runhua $\& \mathrm{Li}, 2006)$. Furthermore, in the 2014 response to the Ebola outbreak in West Africa, CDC not only provided guidance to health-care professionals, but also returned to West Africa to focus on halting the virus's spread.

Table 2. CDC's main development history and memorabilia during 1946-2000

\begin{tabular}{|c|c|}
\hline Time & Main events \\
\hline July 1,1946 & $\begin{array}{l}\text { U.S. Public Health Service re-established the Malaria Control in War Areas as the } \\
\text { Communicable Disease Center with its headquarters in Atlanta. }\end{array}$ \\
\hline 1951 & $\begin{array}{l}\text { Epidemic Intelligence Service was established to train scientists to prepare for } \\
\text { health crises worldwide. }\end{array}$ \\
\hline 1970 & The agency was renamed to the U.S. Disease Control Center. \\
\hline 1980 & $\begin{array}{l}\text { The word "center" was changed to plural to show changes in the structure of the } \\
\text { mechanism. }\end{array}$ \\
\hline 1991 & $\begin{array}{l}\text { "National" was added to the four sub-centers under the center: National Centre for } \\
\text { the Prevention and Promotion of Chronic Diseases, National Centre for } \\
\text { Environmental Health, National Centre for Infectious Diseases, and National Centre } \\
\text { for Preventive Services. }\end{array}$ \\
\hline 1992 & $\begin{array}{l}\text { In 1992, the U.S. Congress renamed the agency again by adding "control" to make } \\
\text { its full name the United States Centers for Disease Control and Prevention. }\end{array}$ \\
\hline 2000 & $\begin{array}{c}\text { CDC has } 11 \text { centers and offices, including the National Center for Infectious } \\
\text { Diseases. }\end{array}$ \\
\hline
\end{tabular}

Source: Centers for Disease Control and Prevention (CDC) website and other web-based information.

\subsection{CDC's Organizational Structure and Core Competencies}

As a main operating department of the U.S. Department of Health and Human Services, CDC has a typical functional organizational structure, with a director and chief deputy director, who directly manage several research centers, institutes, and offices. This helps the CDC be more efficient and effective in dealing with public health issues (Figure 2; CDC, n.d.). Each functional group implements the CDC's proposed solutions in its respective area of expertise while providing in-house support and resource sharing for cross-cutting issues and specific health threats. This function can be divided into three main categories: strategic planning department (health policy and strategy formulation in the last five years), related department for disease prevention and control (infectious and non-communicable diseases), and organizational security department (personnel, communication, laboratory science, security, etc.). Each functional department usually has a head of agency, and the work office under its jurisdiction usually has a principal head. Responsibility and power are clearly divided to facilitate performance communication and accountability. 


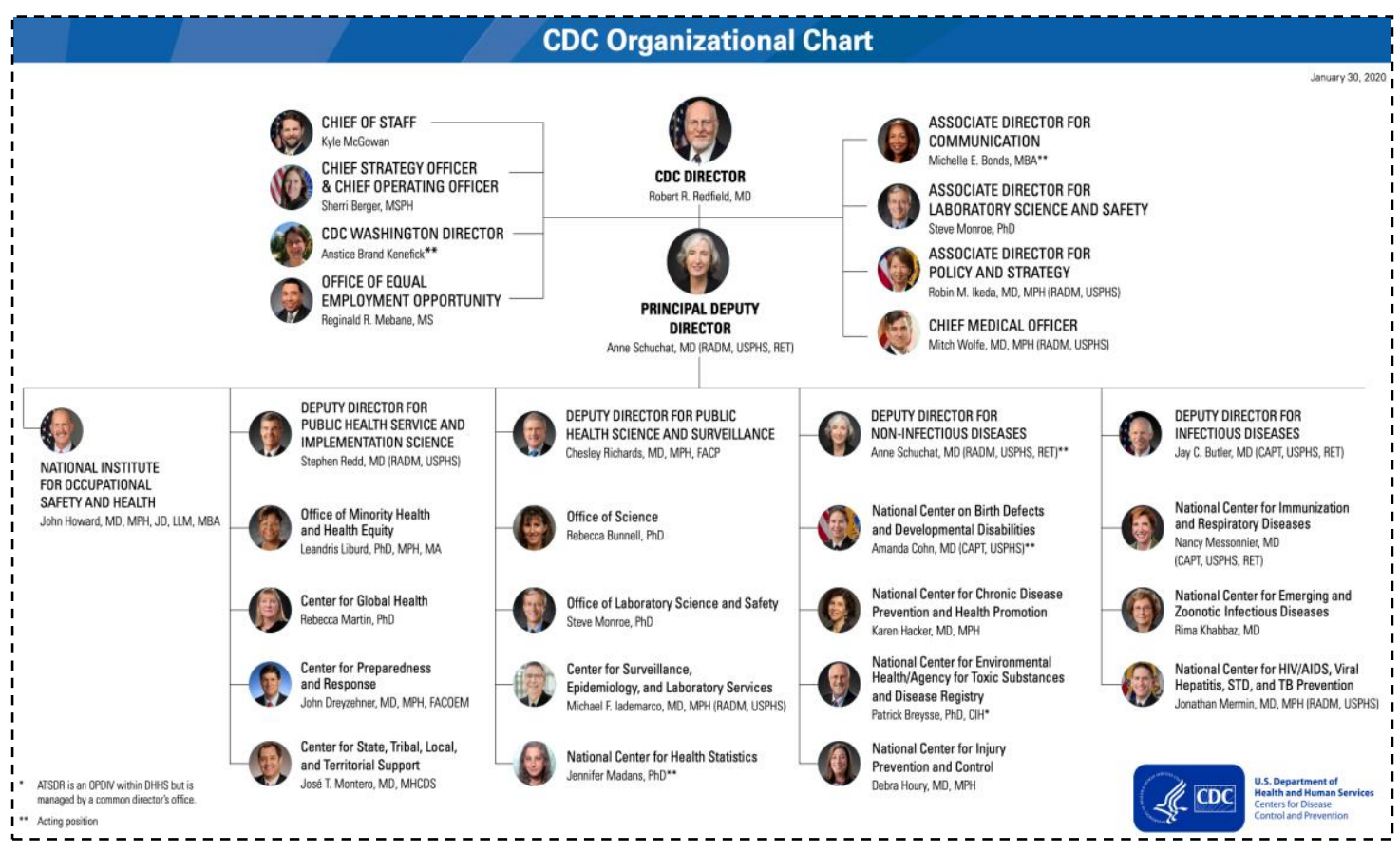

Figure 2. CDC's organizational structure and related functions in the U.S.

Although the CDC has many related functional departments, each has its own clear organizational division of labor and responsibility system, which is convenient for internal management. For example, the Office of the Associate Director for Policy and Strategy also has the Office of the Director; Office of Health System Cooperation; and Office for Policy Research, Analysis, and Development. The sector's overall priorities include identifying high-value prevention and public health policies and interventions; improving understanding and use of credible evidence of the impact of decision makers, health care, and public health on prevention; and promoting cooperation between public health, health care, and other sectors. Moreover, for addressing infectious disease issues, the deputy director of infectious diseases - as the chief adviser to the CDC's director of internal infectious diseases-provides strategic leadership for the CDC's three national centers for infectious diseases and works with internal and external partners to promote infectious disease prevention plans and priority initiatives. The three national centers for infectious diseases have clear responsibilities and division of labor.

A major feature of CDC's organizational structure and management is diversity and inclusive management. The Office of Minority Health and Health Equity (OMHHE) was established within CDC's organizational structure to lead its diversity work by developing a strategic framework that supports policies on diversity. Diversity is an integral part of OMHHE's daily management and public health plans, and diversity of gender, race, ethnicity, and other unique aspects gives the institution a strong and outstanding capacity and ability to carry out health protection and disease prevention for all. As a special management concept, the organization ensures this diversity and creates a positive working environment that fosters appreciation and mutual respect for each employee, gives all employees the opportunity to reach their potential, and contributes to CDC's mission to the maximum extent possible. 


\section{Macrothink}

Journal of Public Administration and Governance

ISSN 2161-7104

2020, Vol. 10, No. 4

CDC's personalized organizational structure has created excellent core business capabilities. These core competencies include optimizing and applying world-class data and analysis; serving as reference laboratories worldwide; maintaining and developing elite public health expertise; and responding quickly to domestic and foreign epidemics based on current strong global health capabilities and domestic preparedness. Moreover, CDC's unique expertise and interdependence in organizational management are highlighted in strategic communication, excellence in operations, partnership building, and stakeholder engagement, which contribute to effective implementation of CDC's strategic framework and focus. Further, core competencies within some CDC organizations are translated into many sub-competencies and implementation initiatives. Specifically, in terms of preparedness and response capacity, the CDC established 15 capacities in 2011 that can be used as national public health preparedness plan standards, and since then these have become an important framework for state, local, tribal, and territorial preparedness plans that reflect their capacity to plan, implement, and assess their preparedness for, and response to, public health incidents (CDC \& Center for Preparedness and Response, 2019). These 15 capacities include, inter alia, community preparedness, community recovery, operational coordination in emergencies, public information and early warning in emergencies, death management, mass care, management and distribution of medical supplies, public health surveillance and epidemic research, non-drug intervention, volunteer management, etc. CDC also attempted to build broad partnerships with governments and non-governmental organizations at all levels to enhance capacity and achieve organizational goals.

\subsection{CDC's Annual Budget and Input}

As the top U.S. public health institution, CDC is funded by the federal government, with sufficient funding each year for disease prevention and control and public health protection. The CDC's budget and expenditure are closely related to their role positioning. Their main role location includes detecting and responding to emerging health threats; responding to the greatest health problems causing death and disability in the U.S.; putting science and advanced technology into action to prevent disease; promoting healthy and safe behavior, communities, and environments; developing leaders and training public health personnel, including for disease detection; and maintaining the country's health and vitality. Accordingly, $\mathrm{CDC}$ has long planned for sustained funding in different areas. Figure 3 depicts the proportion and volatility of CDC's investment in various areas since 2013. 


\section{$\triangle 1$ Macrothink}

Journal of Public Administration and Governance

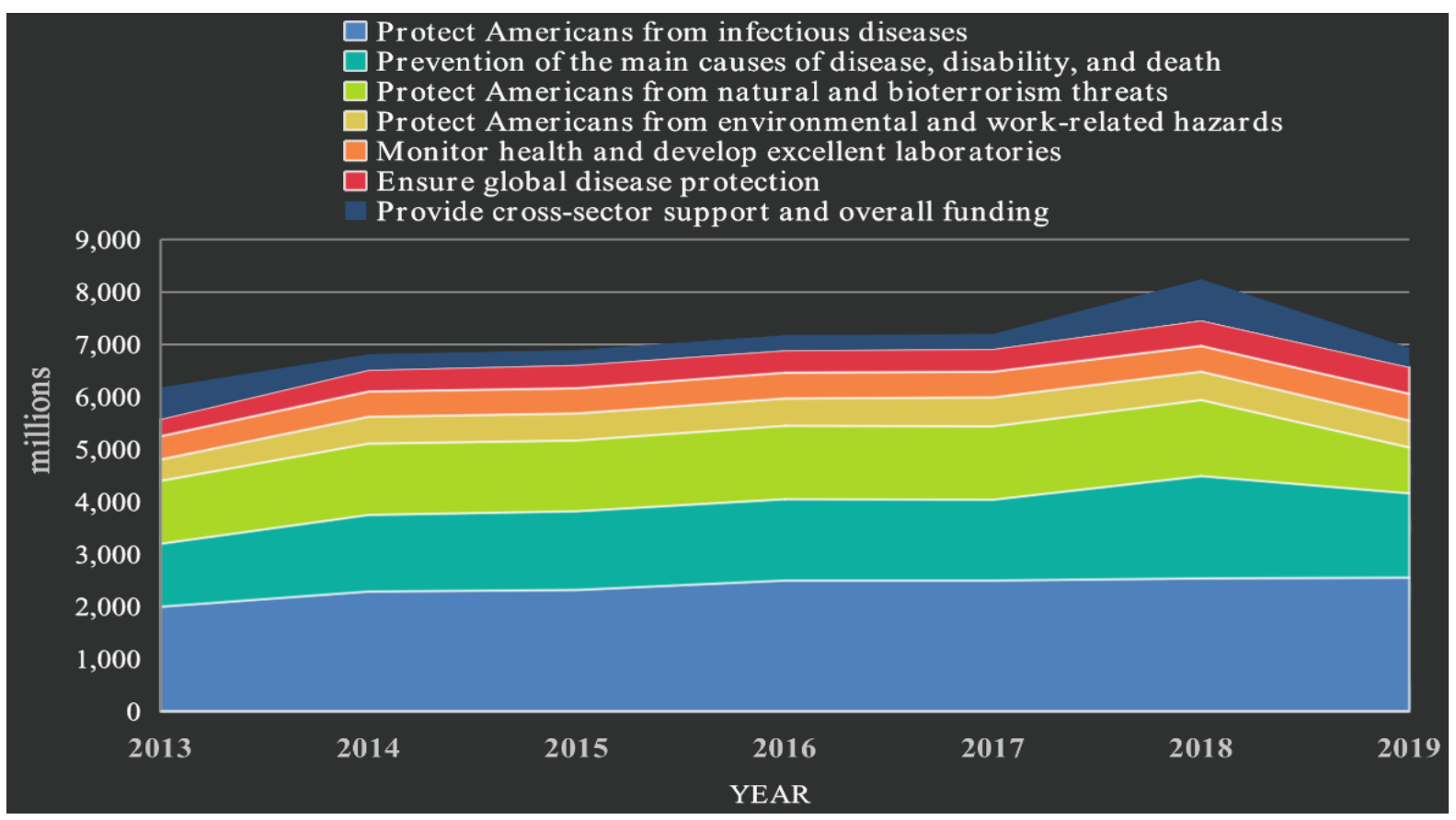

Figure 3. Funding status and areas of the CDC in the U.S. for 2013-2019

As Figure 3 shows, since 2013, CDC's overall budget shows a small growth trend; in the last five years, it has been around $\$ 7$ billion. Particularly, the budget for 2019 reached $\$ 7.3$ billion, where $70 \%$ of the domestic budget is for the state and local health sectors. CDC's budget is open and transparent, and the public can download the annual Operating Plans and Budget Fact Sheets highlighting CDC's priorities in the presidential budget requests. It also outlines each account's tasks, activities, and performance highlights. In addition, each functional department of the CDC formulates its own budget plan according to the overall budget. Figure 3 also reflects the CDC's contribution. The top three areas of highest spending in the past year-protect Americans from infectious diseases; prevent diseases, disabilities, and main causes of death; and protect Americans from natural and biological terrorism-account for about $70 \%$ of the total investment. At the national level, CDC attaches great importance to the life and health of the country's public, as well as to routine health monitoring and laboratory improvement. It is committed to global disease protection, cross-cutting support, and overall funding; the proportion of these funds accounts for about $20 \%$. Moreover, CDC's sustained and stable funding for disease control and public health also indicates the great importance they attach to public health issues and long-term public health strategic planning.

\section{Narrative Analysis of CDC's Prevention and Control of Ebola Virus in the U.S.}

\subsection{Ebola: An Appalling Global Disaster}

During 2014-2015, the Ebola outbreak in West Africa was an unprecedented global disaster, in both scale, duration, and geographical scope. Over 28,000 cases were recorded throughout the course of the virus's spread, resulting in more than 11,000 deaths in Guinea, Liberia, and Sierra Leone. Even in the months before the epidemic's end, it caused far more casualties and losses than the total number of cases reported in all previous outbreaks (Chowell \& Nishiura, 
2014).

The crisis had a devastating impact on the economic and health systems of the three most severely damaged countries. Most business owners, government agencies, and local non-governmental organizations were forced to suspend operations at the peak of the epidemic, which directly exacerbated unemployment and food shortages. Hospitals were closed because of staff shortage; many health-care workers remained home for fear of contracting the virus; and social and economic activities were further restricted by isolation, night curfews, and bans on public gathering. Many people were out of work, even the most common diseases were not treated, corpses of people who died from Ebola were seen on the streets, and civil unrest was common (Morse, Grepin, Blair, \& Tsai, 2016).

Compliance with government-mandated social isolation policies is essential to slow the spread of the virus. However, in poor and backward countries such as Guinea, Liberia, and Sierra Leone, these policies constitute a huge and unprecedented invasion of government authority into the public's daily life. Citizens are forced to comply with isolation rules, report cases and contact tracing, and are required to not take care of relatives with suspected Ebola symptoms nor wash the dead before burial (traditional practice). In Liberia, public gatherings were banned between July 2014 and January 2015; all schools were closed; a curfew came into effect after 6 p.m.; and handshakes, cheek kisses, and strokes were strongly discouraged (Robert, 2017).

\subsection{CDC's Key Contribution to Ebola Control}

CDC's response to Ebola in West Africa is the agency's biggest emergency response in history (Brooks, Pinto, \& Gill, 2016). CDC ran its Emergency Operations Centre (EOC) from July 9, 2014, to March 31, 2016. About 4,000 CDC employees were directly involved, and 1,897 were sent to Guinea, Liberia, Sierra Leone, and other African countries affected by the epidemic (e.g., Nigeria and Mali). CDC's deployed teams include specialists in epidemiology, infection control, laboratory analysis, medical care, emergency management, information technology, health communications, behavioral sciences, anthropology, logistics, planning, and other related disciplines (Beth et al., 2016). Table 3 describes CDC's main contributions to the Ebola virus outbreak in West Africa from March 2014 to July 2015.

Table 3. Main contributions of the Centers for Disease Control and Prevention (CDC) for prevention and control of the Ebola virus epidemic in West Africa (March 2014 to July 2015)

\begin{tabular}{ccc}
\hline Time & Spread of the epidemic & Summary of key contributions and roles \\
\hline $\begin{array}{c}\text { March 2014 } \\
\text { May 2014 }\end{array}$ & $\begin{array}{c}\text { Early reports of Ebola virus from Guinea } \\
\text { Virus spread to Liberia and Sierra Leone }\end{array}$ & CDC created a Field Investigation Team \\
July 2014 & Sharp increase in disease deaths in three & $\begin{array}{c}\text { CDC launched the Emergency Operations Centre; } \\
\text { surge in CDC deployment; CDC level-3 travel } \\
\text { countries }\end{array}$ \\
wid-July 2014 & Virus spread to Nigeria and Senegal & $\begin{array}{c}\text { unnecessary travel to West Africa) } \\
\text { CDC blocked outbreaks in both countries }\end{array}$ \\
August 2014 & Deaths continued to rise in Sierra Leone and & CDC expanded Ebola testing in U.S. laboratories; \\
\hline
\end{tabular}




\section{Macrothink Institute ${ }^{\text {TM }}$}

Liberia and to decline in Guinea

Mid-August 2014

September 2014 to mid-October 2014

Mid-October 2014

to November 2014

Mid-April 2015 to

May 2014

June 2015 to July 2015
Guinea's death toll reached its first peak

Guinea's death toll began to fall to a second peak; Liberia's death toll peaked; Sierra Leone's death toll peaked; Ebola carriers arrived in Dallas, U.S., and two nurses were infected

Deaths peaked in Sierra Leone and declined in Guinea and Liberia; virus spread to Mali

The outbreak in Liberia was declared closed for the first time; the other two countries were almost at an end

Liberia reported a small number of new cases in mid-June established laboratories in Sierra Leone CDC Director Dr. Thomas Frieden personally travelled to Guinea, Liberia, and Sierra Leone CDC held micro-planning workshop with county leaders in Liberia; conducted enhanced inspections at the airport; implemented new tracking plans for suspected individuals with infection from Ebola outbreak countries; organized a safety course for health workers among West African volunteers in Aniston, Alabama; and helped quickly control the new outbreak in Liberia through the rapid isolation and treatment of Ebola team

CDC prepared to improve hospitals in partnership with the affected countries; CDC teams blocked outbreaks in Mali

CDC deployed 1,000 staff members

CDC recommended reducing screening of Liberian passengers; CDC Emergency Operations Centre was launched for a full year

Source: CDC website and other web-based information

\subsection{CDC's Key Interventions for Ebola Control}

CDC's effective interventions to fight against Ebola in West African countries can be divided into three main areas: a rapid response emergency management system, specialized technical tools, and strong organizational support and cooperation network.

First, the emergency management system of rapid response was seen soon after the outbreak. CDC rapidly launched the EOC, established the Emergency Management Development Team (EMDT), sent a large number of personnel for local response to the epidemic, rapidly isolated and treated infected persons, and strengthened the control of border health and security measures. Specifically, except for the start-up EOC, CDC established a dedicated EMDT. Within its Incident Management System (IMS) architecture, in September 2014, the team's main task was to provide technical assistance to affected countries; improve emergency management capacities in Guinea, Liberia, and Sierra Leone, and other high-risk countries (e.g., Gambia, Mauritania, Togo, Benin, and Nigeria) that are not yet infected; address significant gaps in emergency management in these countries; and carry out relief work in clear accordance with established principles of emergency management (Brooks et al., 2016). Based on the establishment of emergency management teams, rapid isolation and treatment of virus patients are important strategies in the emergency management system to prevent virus outbreaks. Beginning in early October 2014, the CDC quickly designed and helped 
implement a Liberian strategy for rapid isolation and treatment of Ebola virus, allowing for faster control of the outbreak, providing support to patients in remote areas, effectively reducing the outbreak's duration, and doubling the infected persons survival rate, according to relevant documentation (Kateh et al., 2015). Strengthening border health and security monitoring are also part of emergency management. CDC, in cooperation with the ministries of health and airport authorities of the three most affected countries, such as Guinea, and other affected countries, conducted strict screening of passengers who left the country by air for timely detection of virus carriers. By the first half of 2015, more than 200,000 passengers were screened out of Guinea, Liberia, and Sierra Leone, effectively controlling the virus's further spread and reducing panic among airline crew and regular passengers.

Second, specialized technical means and tools play a great role in CDC's prevention and control of the epidemic. (1) Technical guidelines guide disease prevention and control. CDC has published more than 200 scientific documents, including more than 100 technical guidance documents related to the response to various outbreaks and crises, and CDC staff have worked closely with, inter alia, UNICEF and other partners to develop guidance documents in related areas, such as reopening school safety guidelines (UNICEF, CDC, \& WHO, 2015). (2) Accurate epidemic simulation is key to increasing the speed and scale of the U.S. and global response. CDC projected a sustained, rapid, and moderate trend of the epidemic during August 2014 and predicted the worst possible consequences while stimulating a broad response from different agencies worldwide (Meltzer, 2014). The model predicted an exponential increase in the number of cases and the need for a large and urgent response, which contributed to the widespread mobilization of CDC's internal and external forces in response to the epidemic. The model also predicted the serious consequences of delays in interventions, which, without timely patient isolation, treatment, and proper burial, would double the number of cases per month. This model thus contributed to the CDC's dedication to the race against "death," in three severe epidemic countries, all political and social forces were extensively engaged and acted upon (African Union, 2015). The model also predicted the tipping point of the outbreak, a finding that prompted the CDC to quickly establish community isolation facilities and rehearse exercises to ensure orderly rescue work (The White House, 2014). After the above effective intervention, the model prediction results fit well and were very consistent with the actual case trajectory. (3) Active exploration of the adoption of emerging technologies and rational use of vaccines is required. On the one hand, scientists from CDC's experimental institutions promoted the development of lateral flow assays for detecting Ebola virus on-site and in immediate environments by using robotics to enhance high-throughput laboratory-building capabilities and collaborating with enterprises in research and development. On the other hand, in addition to supporting the U.S. National Institutes of Health in conducting randomized controlled trials for Ebola virus treatment and vaccines, CDC collaborated with the Sierra Leone Health System in parallel trials to introduce vaccines against Ebola and phase-in trials (Clinical Trials.gov, n.d.).

Again, strong organizational support and cooperation networks have laid an important material foundation for CDC's fight against the epidemic. Organizational support and cooperation network are mainly reflected in the following aspects: (1) CDC provides 
professional training and technical guidance for countries facing epidemics. CDC, for example, partners with the Office of Foreign Disaster Assistance, WHO, and the U.S. Department of Defense to provide technical support and training for establishing Ebola treatment units and community care centers in the areas of origin. CDC also conducted infection control training with its partners for more than 25,000 medical staff in three disaster-ridden countries, including Guinea, as well as hands-on training courses for more than 600 U.S. health-care providers on Ebola clinical care and infection control (prior to arrival in West Africa; Beaglehole \& Yach, 2003; CDC, 2015b). (2) CDC actively promotes effective dissemination of health information in countries facing epidemics. CDC's risk communication experts quickly generate and disseminate accurate epidemic information, end rumors, reduce gossip, control local unsafe burial habits, and respond positively to community needs. CDC's staff identified and promulgated burial measures in Liberia and Sierra Leone to meet the mourning needs of local communities for cultural practices, while disseminating effective burial knowledge and information and reducing local resistance to safe burial (Nielsen et al., 2015). In short, effective communication and dissemination of information are key strategies for successful prevention and control of the epidemic. (3) CDC quickly set up a laboratory and conducted sample testing. On the one hand, the CDC, in cooperation with the EU laboratory, provided regular and quantitative reverse transcription polymerase chain reaction technology for patients with suspected cases and the deceased in severely affected countries; on the other hand, CDC sector experts helped coordinate IMS laboratories, supported laboratories in Liberia with the U.S. Department of Defense and National Institutes of Health, and processed more than 2,000 samples for field laboratories in Sierra Leone in the three most severe weeks (CDC, 2015a). (4) CDC is committed to extensive cooperation with domestic and foreign expert bodies. CDC's epidemiological experts within the organization work extensively with governments, non-governmental organizations, and WHO to organize training staff to carry out epidemic prevention and control activities and provide support for clinical research, public health, laboratories, medical facilities, data systems, etc. CDC also advocates active participation of the Disaster Assistance Response Team (DART) of the U.S. Department of Defense and the U.S. Agency for International Development, which deployed 3,000 military personnel for logistical support and coordination, while DART partners responsible for quickly attracting service delivery and supporting epidemic response plans were actively involved (UNICEF et al., 2015). Thus, CDC cooperation with experts and institutions and orderly organization and coordination in the epidemic are important for epidemic control.

\section{Conclusion: Implementation Framework and Enlightenment of Major Epidemic Prevention and Control}

The Ebola outbreak in West Africa is an unprecedented disaster in modern human history that resulted in a painful blow to local economic and social development and infrastructure construction. While fighting Ebola in West Africa, the CDC played a major role in all aspects If decisive action and global relief can be undertaken when the outbreak starts, the number of people eventually infected and killed by the virus as well as social and economic losses will be significantly reduced. Through a narrative analysis of the CDC's current organizational 
structure, functional configuration, funding input, and response to Ebola, the implementation framework of public health institutions in responding to major outbreaks can be refined (see Figure 4). The implementation framework in Figure 4 shows that, for the top public health institutions in the country, such as the CDC, two main strengths and features have emerged in response to Ebola: effective organizational structures and systems, and rapid response epidemic management capabilities. Both these advantages and characteristics have penetrated the construction of the IMS, adoption of specialized technical means and tools in the prevention and control of Ebola virus disease, a wide range of cooperation networks and organizational coordination, and other aspects. By combining information on CDC's organizational structure and functional configuration and their important initiatives in the fight against Ebola, and interpreting the implementation framework of Figure 4, this study suggests that public health agencies should bear the brunt of the following in preventing and controlling major outbreaks: "institution building" and "capacity enhancement." These two tasks should always run through the whole process of epidemic prevention and control.

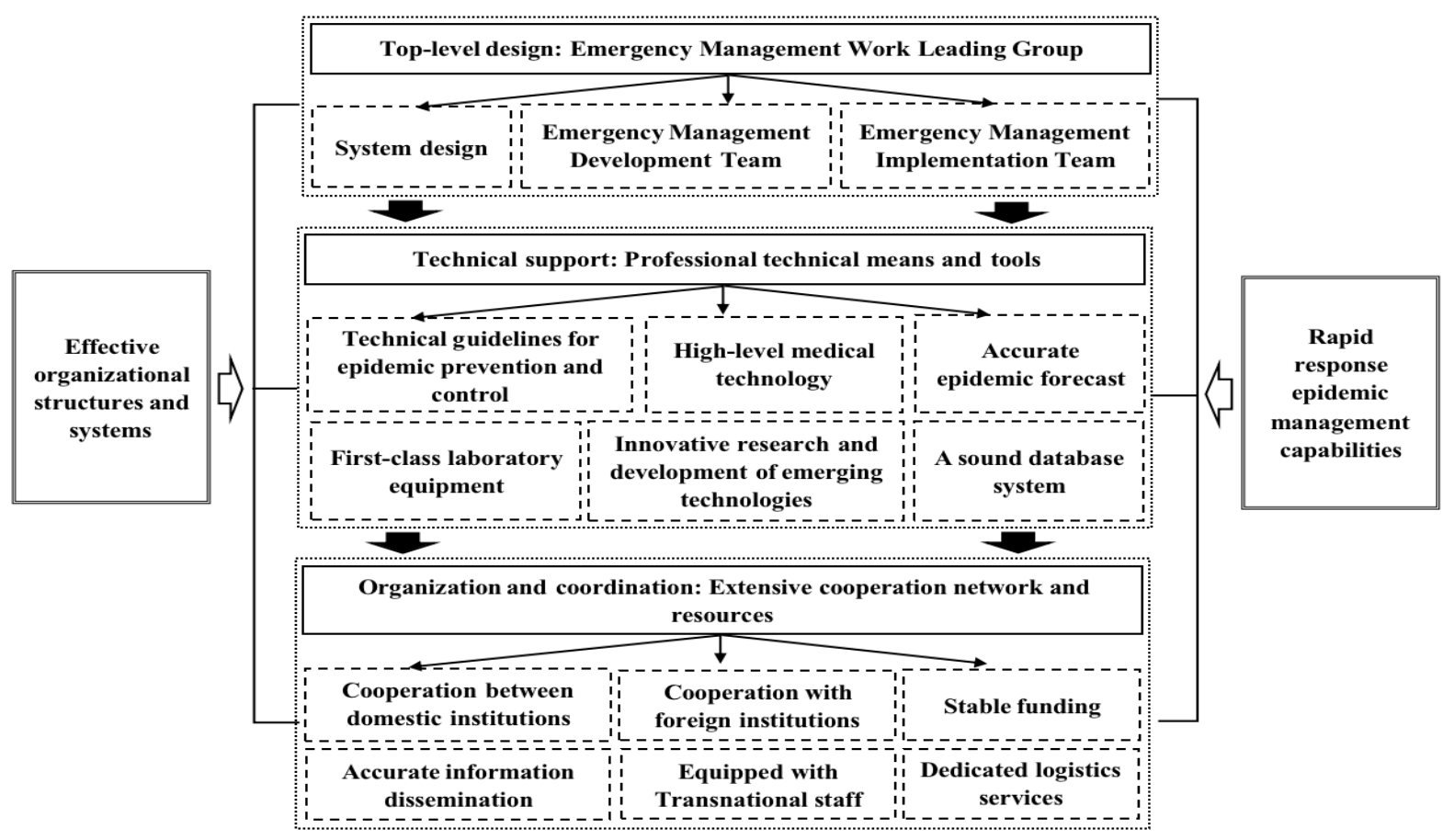

Figure 4. CDC's implementation framework for the Ebola virus control process

Specifically, on the one hand, before a major outbreak (in daily work), public health institutions need to constantly improve the emergency management system. The CDC has formed a stable and efficient organizational structure after more than 70 years of organizational and operational changes and has adopted a unified IMS to enhance its emergency coordination ability. Since the beginning of Ebola prevention and control, the CDC quickly started the IMS and EOC and put forward phased deployment and implementation of the emergency management strategy. The emergency management team's responsibilities and requirements are fully explained, which provides an important organizational guarantee for the epidemic's successful control. As a result, the CDC's experience shows that in the aspect of system construction, public health institutions should 
review the situation, base themselves on national conditions, set up regular emergency management agencies, and improve and perfect the standardized emergency management system as soon as possible, so as to carry out smooth emergency coordination for epidemic prevention and control. When dealing with sudden outbreaks, public health institutions need to make correct decisions and respond quickly, start the emergency management system as quickly as possible, fully configure and mobilize the emergency management team, carry out rescue activities in time, and try their best to control further spread of the epidemic.

On the other hand, for preventing and controlling major outbreaks, public health institutions should give full play to their emergency response and management capabilities. First, public health institutions and staff should be good at efficient use of scientific and professional technical means and tools. CDC actively used model simulation, robot technology, and other emerging technologies for epidemic prevention and control, explored the use of advanced experimental equipment and other professional technical tools, improved the level of diagnosis and treatment of Ebola virus, accurately predicted the development trend of the epidemic, and made breakthroughs in vaccine research and development. Therefore, public health institutions should introduce advanced experimental equipment and explore various medical techniques and tools to improve the level of virus cure. Simultaneously, public health institutions should master high levels of medical technology and big data tools for vaccine development and epidemic trend prediction to maximize the control of further outbreaks. Moreover, they should formulate various technical guidelines to provide scientific guidance for epidemic prevention and control. Second, public health institutions should be good at establishing a wide network of cooperation and give full play to the role of organization and coordination. When preventing and controlling the Ebola epidemic, CDC established cooperative relations with various authoritative organizations at home and abroad, integrated various forces, and coordinated the epidemic response. This promoted the smooth development of epidemic prevention and control in epidemic areas and provided an important guarantee for effective control of the Ebola epidemic in technical and material aspects. Therefore, public health institutions should make concerted efforts to strengthen extensive cooperation with all kinds of medical and administrative institutions at home and abroad; give play to the advantages of different teams in the system and technology in the fight against the epidemic; and carry out orderly organization and coordination in all aspects of financial support, information dissemination, staffing, logistics support, etc., to promote gradual success of epidemic prevention and control.

\section{Acknowledgments}

This article is the phased result of the project of the Public Scientific Literacy Improvement Plan (New Coronavirus Infection Pneumonia Emergency Science) project [2020PSL(Y)029] in Shaanxi Province, China.

\section{References}

African Union. (2015). West Africa fact sheet: African Union response to the Ebola epidemic in West Africa. Retrieved from http://pages.au.int/sites/default/files/FACT\%20SHEET_as\%202015.pdf 
Anderson, J. C., \& Gerbing, D. W. (1988). Structural equation modeling in practice: A review and recommended two-step approach. Psychological Bulletin, 103(3), 411-423. https://doi.org/10.1037/0033-2909.103.3.411

Beaglehole, R., \& Yach, D. (2003). Globalisation and the prevention and control of non-communicable disease: The neglected chronic diseases of adults. Lancet, 362(9387), 903-908. https://doi.org/10.1016/S0140-6736(03)14335-8

Beth P. Bell, Inger K. Damon, Daniel B. Jernigan, Thomas A. Kenyon, Jordan W. Tappero. (2016). Overview, control strategies, and lessons learned in the CDC response to the 2014-2016 Ebola epidemic. Morbidity and Mortality Weekly Report, 65(3), 4-11. https://doi.org/10.15585/mmwr.su6503a2

Brooks J. C., Pinto M., \& Gill A. (2016). Incident management systems and building emergency management capacity during the 2014-2016 Ebola epidemic-Liberia, Sierra Leone, and Guinea. Morbidity and Mortality Weekly Report Supplements, 65(3), 12-20. https://doi.org/10.15585/mmwr.su6503a5

Campbell-Lendrum, D., Manga, L., Bagayoko, M., \& Sommerfeld, J. (2015). Climate change and vector-borne diseases: what are the implications for public health research and policy?. Philosophical Transactions of the Royal Society B: Biological Sciences, 370(1665), 20130552. https://doi.org/10.1098/rstb.2013.0552

CDC. (2020). CDC Strategic Framework. Retrieved from https://www.cdc.gov/about/organization/strategic-framework/index.html

Centers for Disease Control and Prevention (CDC). (n.d.). Retrieved from https://www.cdc.gov/about/organization/cio.htm

CDC. (2015a). Improving Ebola diagnostics: Field lab in Bo, Sierra Leone. Retrieved from http://www.cdc.gov/ncezid/dhcpp/featured_stories/improving-ebola-diagnostics.html

CDC. (2015b). Preparing healthcare workers to work in Ebola treatment units (ETUs) in Africa. Retrieved from http://www.cdc.gov/vhf/ebola/hcp/safety-training-course

CDC \& Center for Preparedness and Response. (2019). Public health emergency preparedness and response capabilities: National standards for state, local, tribal, and territorial public health. Retrieved from https://www.cdc.gov/cpr/readiness/capabilities-change.htm

Chowell, G., \& Nishiura, H. (2014). Transmission dynamics and control of Ebola virus $\begin{array}{llllll}\text { disease (EVD): A } & \text { A review. }\end{array}$ https://doi.org/10.1186/s12916-014-0196-0

Clandinin, D. J., \& Connelly, F. M. (2003). Narrative inquiry: Experience and story in qualitative research. Taipei: Psychology Press Co., Ltd.

Clinical Trials.gov. (n.d.). Putative investigational therapeutics in the treatment of patients with known Ebola infection. Retrieved from https://clinicaltrials.gov/ct2/show/NCT02363322

Fu, M., \& Tian, H. (2008). Educational narrative research: Essence, characteristics and methods. Educational Research, 05, 36-40.

Gao, H. (2020). The methodology of narrative research and educational research: Features, 
contributions and limitations. Educational Development Research, 40(04), 24-31.

GUBlER, D. J., CAMPBELL, G. L., NASCI, R., KOMAR, N., PETERSEN, L., \& ROEHRIG, J. T. (2000). West Nile virus in the United States: guidelines for detection, prevention, and control. Viral immunology, 13(4), 469-475. https://doi.org/10.1089/vim.2000.13.469

Henderson D. A., Inglesby, T. V., Bartlett, J. G., Ascher M. S., Parker G.. (1999). Smallpox as a biological weapon: Medical and public health management.Journal of the American Medical Association, 281(22), 2127-2137. https://doi.org/10.1001/jama.281.22.2127

Hu, R., \& Li, L. (2006). Introduction to the U.S. Centers for Disease Control and Prevention. Chinese Journal of Medical Science Research Management, 1, 65-66+50.

Joet, G. B., Martin, S. A., \& Anne M. (2004). Conquering the intolerable burden of malaria: What's new, what's needed: A summary. American Journal of Tropical Medicine and Hygiene, 71(2), 1-15. https://doi.org/10.4269/ajtmh.2004.71.2_suppl.0700001

Jones, D., MacDonald, G., Volkov, B., \& HerreraGuibert, D. (2014). Evaluation of field epidemiology training programs: Findings and recommendations. Atlanta, GA: CDC. Retrieved from https://www.cdc.gov/globalhealth/healthprotection/fetp/pdf

Joseph, H., Stancliff, S., Langrod, J. (2000). Methadone maintenance treatment (MMT): A review of historical and clinical issues. Mount Sinai Journal of Medicine, 67(5), 347-364.

Kateh, F., Nagbe, T., Kieta, A., Barskey A., \& Nyenswah, T. (2015). Rapid response to Ebola outbreaks in remote areas-Liberia, July-November 2014. Morbidity and Mortality Weekly Report, 64, 188-192.

Meltzer, M. I., Atkins, C. Y., Santibanez, S., Knust B., \& Washington, M. L. (2014). Estimating the future number of cases in the Ebola epidemic-Liberia and Sierra Leone, 2014-2015. MMWR Surveill Summ, 63(S3), 1-14.

Morse, B., Grepin, K. A., Blair, R. A., \& Tsai, L. (2016). Patterns of demand for non-Ebola health services during and after the Ebola outbreak: Panel survey evidence from Monrovia, Liberia. BMJ Global Health, 1(1), e000007. https://doi.org/10.1136/bmjgh-2015-000007

Mukherjee, S. (2017). Emerging infectious diseases: Epidemiological perspective. Indian Journal of Dermatology, 62(5), 459-467.

Nielsen, C. F., Kidd, S., Sillah, A. R., Davis, E., \& Kilmarx, P. H. (2015). Improving burial practices and cemetery management during an Ebola virus disease epidemic-Sierra Leone. Morbidity and Mortality Weekly Report, 64, 20-27.

Panchaud, A., Stojanov, M., Ammerdorffer, A., Vouga M., \& Baud, D. (2016). Emerging role of Zika virus in adverse fetal and neonatal outcomes. Clinical of Microbiology Reviews, 29, 659-694. https://doi.org/10.1128/CMR.00014-16

Robert, A. B., Benjamin, S. M., \& Lily L. T. (2017). Public health and public trust: Survey evidence from the Ebola virus disease epidemic in Liberia. Social Science \& Medicine, 172, 89-97. https://doi.org/10.1016/j.socscimed.2016.11.016

Schneider, D., Evering-Watley, M., Walke H., Bloland P. B. (2011). Training the global public health workforce through applied epidemiology training programs: CDC's experience (1951-2011). Public Health Review, 33, 190-203. 
Schuchat, A., Tappero, J., \& Blandford, J. (2014). Global health and the US Centers for Disease Control and Prevention. Lancet, 384, 98-101. https://doi.org/10.1016/S0140-6736(14)60570-5

Shinde, V., Bridges, C. B., Uyeki, T. M., Shu B., Balish, A., Xu, X., \& Lindstrom S., et al. (2009). Triple-reassortant swine influenza A (H1) in humans in the United States, 2005-2009. New England Journal of Medicine, 360, 2616-2625. https://doi.org/10.1056/NEJMoa0903812

Smith, D. H., Pepin, J., \& Stich, A. H. R. (1998). Human African trypanosomiasis: An emerging public health crisis. British Bulletin Medicine, 54(2), 341-355. https://doi.org/10.1093/oxfordjournals.bmb.a011692

The White House. (2014). The White House fact sheet: Update on the Ebola response. Retrieved from https://www.whitehouse.gov/the-press-office/2014/12/02/fact-sheet-update-ebola-response

UNICEF, CDC, \& World Health Organization. (2015). Key messages for safe school operations in countries with outbreaks of Ebola. Retrieved from http://www.cdc.gov/vhf/ebola/pdf/ebola-safe-schoolmessages2015.pdf

US Department of State. (2015). Digital IIP-White House facts on progress in Ebola response in U.S. abroad. Retrieved from http://iipdigital.usembassy.gov/st/english/texttrans/2015/02

Weaver, S. (2013). Urbanization and geographic expansion of zoonotic arboviral diseases: Mechanisms and potential strategies for prevention. Trends Microbiology, 21, 360-363. https://doi.org/10.1016/j.tim.2013.03.003

World Health Organization. (2014). Global alert and response: Ebola virus disease in Guinea. Retrieved from http://www.who.int/csr/don/2014_03_23_ebola/en/2014

Wu, J., Ma, L., \& Zheng, Y. (2009). How the international evaluation of science foundation reports performance-A narrative analysis of the performance report of the Japan Society for the Promotion of Science. Science of Science and Management of Science \& Technology, $30(12), 55-59+69$.

$\mathrm{Xu}$, B. (2015). Summary of narrative research methods. Educational Theory and Practice, 16, $28-30$.

Yan, B., Wu, J., \& Ma, L. (2010). Narrative analysis of performance reporting and performance accountability-The NSF of the United States of America. Scientific Research, 28(11), 1619-1628.

Yuan, Z. (2020). Summary of US crisis response. People's Forum, 10, 16-19.

Zimmet, P. (2000). Globalization, coca-colonization and the chronic disease epidemic: Can the doomsday scenario be averted? Journal of Internal Medicine, 247, 301-310. https://doi.org/10.1046/j.1365-2796.2000.00625.x 


\section{Copyright Disclaimer}

Copyright for this article is retained by the author(s), with first publication rights granted to the journal.

This is an open-access article distributed under the terms and conditions of the Creative Commons Attribution license (http://creativecommons.org/licenses/by/4.0/). 